\title{
A Study of Malnutrition-dependent Factors among Under-five Children in Ekureku Community, Abi Local Government Area of Cross River State, Nigeria
}

\author{
Etim, Kimboline Donatus ${ }^{{ }^{\star}}{ }^{\star}$ Ejemot-Nwadiaro, Regina Idu ${ }^{1}$ \\ and Kalu, Randymay $\mathrm{Eja}^{2}$ \\ ${ }^{1}$ Department of Public Health, University of Calabar, Calabar, Nigeria. \\ ${ }^{2}$ Federal Medical Center, Yenogoa, Bayelsa State, Nigeria.
}

\begin{abstract}
Authors' contributions
This work was carried out in collaboration between all authors. Author EKD designed the study and wrote the first draft of the manuscript under the supervision of author ENRI who read, edited and arranged the field experiments. Author KRE managed the literature databases and statistical analyses of the study. All authors read and approved the final manuscript.

Article Information

DOI: 10.9734/BJMMR/2017/30204

Editor(s):

(1) Rui Yu, Environmental Sciences \& Engineering, Gillings School of Global Public Health, The University of North Carolina at Chapel Hill, USA.

Reviewers:

(1) Piero Valentini, Catholic University of the Sacred Heart, Rome, Italy.

(2) J. U. Nwamarah, University of Nigeria Nsukka, Nigeria. Complete Peer review History: http://www.sciencedomain.org/review-history/19133
\end{abstract}

Original Research Article

Received $25^{\text {th }}$ October 2016 Accepted $8^{\text {th }}$ December 2016 Published $19^{\text {th }}$ May 2017

\section{ABSTRACT}

Malnutrition is the consumption of dietary nutrients either insufficiently or exclusively, and several socio-economic, ignorance, and educational factors are known to determine nutritional status of any community. This study aimed at examining the nutritional status and malnutrition-dependent factors in Ekureku Community. With a cross-sectional design, 380 mother-child pair respondents were selected using systematic sampling technique. Nutritional anthropometry and questionnaire were used to gather data. Data collected were entered and analysed using Statistical Package for Social Sciences. Student t-test and Chi-square were used to test for inferential statistics at 5\% level of significance. Results show that $108(28.4 \%)$ of under-five children were stunted, $47(12.3 \%)$ wasted and $107(28.1 \%)$ underweight. Malnutrition was observed to be significantly higher among females than male children $(P<0.05)$. Children aged $>24$ months were more stunted $(22.4 \%)$, 
wasted (9.5\%) and underweight (22.1\%) than children <24 months. Most respondents (54.2\%) had poor knowledge of child nutrition, while $45.8 \%$ had a fair knowledge. Respondents $(35.0 \%)$ breastfed their babies exclusively, while $63.0 \%$ introduced complementary feeding when their children were less than six months old. Factors such as poor maternal education, sex of child, unemployed women, knowledge of child nutrition and poor feeding practice were found to be associated with malnutrition among under-five children. These findings indicate that malnutrition is high among under-five children and may increase child morbidity and mortality in the community.

Keywords: Nutritional status; malnutrition; under-five children; knowledge of nutrition; Ekureku community.

\section{INTRODUCTION}

Malnutrition is the consumption of dietary nutrients either insufficiently or exclusively. Different forms of malnutrition exist which include micronutrient malnutrition, under-nutrition and over-nutrition [1]. Children who are malnourished often fail to thrive, are more likely to suffer from impaired physical and intellectual growth which make them less productive during adulthood [1]. Also, poor school performance, school absenteeism, reduced intellectual achievement, delayed cognitive development morbidity and mortality are common effects of malnutrition among under-five children [2].

In low and middle income countries (LMICs), an estimated 10 million children die from treatable and preventable illnesses annually [3]. Estimates suggest that one-third of childhood mortality is attributable to malnutrition, and Sub-Saharan African and Southern Asian Countries bear a disproportionate burden of malnutrition (90\%) among under-five children [4,5]. Existence of poverty, especially in poor countries drives the proliferation of malnutrition in children [6].

In Sub-saharan Africa, high rates of child mortality can result from factors such as low calories intake, high rates of HIV/AIDS, political instability, poor implementation of government policies, conflicts among groups, etc. For instance, in countries such as Malawi, Burundi and Madagascar, about $50 \%$ of children are stunted as a result of poor dietary intake or poor consumption of vital nutrients [7]. In Nigeria, it has been reported that $50 \%$ of childhood mortality is caused by malnutrition out of an estimated $80 \%$ mortality and $90 \%$ morbidity rates in under-five children, arising from four principal causes which include acute respiratory infection, malaria, diarrhoea and vaccine preventable diseases [8]. Country specific evidence shows that Nigeria has been identified as one of the most affected countries by malnutrition [9].
Malnutrition largely accounts for $49 \%$ school absenteeism and affects over $42 \%$ of children of school age in Nigeria [10].

Several empirical studies have identified factors that affect under-five children's nutritional status. These factors include poverty, failure to breastfeed exclusively, maternal factors such as poor nutrition during pregnancy, lack of appropriate weight gain, illnesses like diarrhoea, acute respiratory infection, poor consumption of vitamin supplements or fortified foods, large family size, poor sanitation, lack of education and information about good or adequate nutrition and food insecurity and safety $[2,11,5,12,13]$. The cycle of undernutrition continues to perpetuate especially in situations where malnourished mothers give birth to underweight babies [14].

Ekureku is a community in Abi Local Government Area of Cross River State, Nigeria. The inhabitants are significantly poor, and this affects many aspects of their livelihood including the nutritional status of their children. Moreover, no research on nutrition has ever been carried out in Ekureku community. Therefore, this study aimed at determining factors affecting nutritional status among under-five children in Ekureku community.

\section{MATERIALS AND METHODS}

\subsection{Study Design}

A descriptive-cross-sectional study was employed to identify the factors of nutritional status of children under-five years in Ekureku community, Abi Local Government Area of Cross River State.

The study population comprised all children between 0-59 months of age, and the sample size was determined using the formula $n=$ $\frac{z q^{2} p_{q}}{d^{2}}$, where $\mathrm{n}$ is sample size, $\mathrm{Z}$ is $95 \%$ 
confidence interval, $d$ is acceptable margin of error and $\mathrm{q}$ is probability of under-five children who are stunted [15]. This gave a sample size of 301. However, to make room for non-response and attrition bias, the desired sample size was increased by $30 \%$ giving a sample size of 390 that was used for the study.

\subsection{Sampling Procedure}

Systematic random sampling technique was used to select every household with children under-five years within the study area. This process started near the market square which is the entrance of the community and continued until 390 households were duly selected to participate in the study.

In each household, caregivers/mothers resident in sampled households with under-five children were administered a set of questionnaires. In polygamous homes with many under-five children from different mothers, only one mother with an under-five child was recruited to partake in the study using lottery method.

\subsection{Instruments for Data Collection}

The instrument for data collection was a semistructured questionnaire that was administered to respondents with both open and closed ended questions. The questionnaire comprised five sections with 37 items. Sections A, B and C covered mother, child and household characteristics respectively, while sections $D$ and E covered mother's nutritional knowledge and health seeking behaviour and child feeding practices, respectively.

\subsection{Nutritional Status Assessment Using Anthropometry}

Nutritional anthropometry is a technique that measures the physical dimensions and gross composition of the human body as a way of assessing nutritional status. Several variables such as child's age, sex, height and weight are measured to carry out the anthropometric analysis. These measurements were used in generating indices such as height-for-age, an index of stunting or small stature for the age, a reflection of chronic or longstanding undernutrition; weight-for-age, index of underweight a composite of acute and chronic undernutrition and weight-for-height, index of wasting a reflection of acute undernutrition. The indices generated were compared with WHO standard classification system of malnutrition to obtain the Z-scores values. The Z-scores values were determined for under-five children of ages 0-12, 13-24, 25-36, 37-48 and 49-59 months. The cut-off values of prevalence of these undernutrition indices considered to be of public health significance are $\geq 20 \%$ for stunting, $\geq 10 \%$ for underweight and $\geq 5 \%$ for wasting [1].

In obtaining the nutritional anthropometric indices, the percent underweight, percent stunting and percent wasting, the proportion of number of children with weight-for-age, number of children with height-for-age and number of children with weight-for-height to total number of children weighed, were respectively calculated.

In measuring the height, children who were yet to walk, were asked to lie on a board placed on a stable surface, and the measurement was taken to the nearest $0.1 \mathrm{~cm}$. For children who were above two years, the height was measured using a meter rule and reading was taken in centimeters. Also, in measuring the weight, children were asked to stand on the middle of the weighing scale's surface. When the child was settled and the reading was stable, measurements were taken to the nearest $0.1 \mathrm{~kg}$. For toddlers and infants, a salter hanging scale was used to take the measurement.

\subsection{Method of Data Analysis}

The data were analysed using the Statistical Package for Social Sciences Software (SPSS 20.0 Version, 2012). Results were expressed as percentages and presented in tables, charts and graphs. Students t-test and chi-square were used to test for the hypothesis stated at $5 \%$ level of significance.

\subsection{Ethical Consideration}

Ethical approval was obtained from Cross River State Research Ethics Committee, Ministry of Health. Informed consent was duly sought and obtained from the respondents who took part in the study. The research participants were assured of the confidentiality of the information obtained.

\section{RESULTS}

Out of 390 questionnaires that were administered to the respondents, 380 questionnaires were received for analysis, giving a respondent rate of $97.4 \%$. 
Table 1. Distribution of respondents by age, religion, education and marital status $(\mathrm{N}=\mathbf{3 8 0})$

\begin{tabular}{lll}
\hline Variables & $\begin{array}{l}\text { Number of } \\
\text { respondents }\end{array}$ & Percentage \\
\hline Age (in years) & & \\
$15-18$ & 8 & 2.1 \\
$19-24$ & 21 & 5.5 \\
$25-29$ & 130 & 34.2 \\
$30-34$ & 109 & 28.7 \\
$35-39$ & 53 & 13.9 \\
$40-44$ & 41 & 10.8 \\
$45-49$ & 18 & 4.7 \\
Total & 380 & 100 \\
Religion & & \\
Christianity & 359 & 94.5 \\
Muslims & 0 & 0.0 \\
Traditional religion & 21 & 5.5 \\
Total & 380 & 100 \\
Education & & \\
No formal education & 58 & 15.3 \\
Primary education & 108 & 28.4 \\
Secondary education & 145 & 38.2 \\
Tertiary education & 69 & 18.1 \\
Total & 380 & 100 \\
Marital status & & \\
Single & 82 & 21.6 \\
Married & 283 & 74.5 \\
Widowed & 0 & 0.0 \\
Separated & 15 & 3.9 \\
Divorced & 0 & 0.0 \\
Total & 380 & 100 \\
\hline & &
\end{tabular}

\subsection{Socio-demographic Characteristics of Mothers/Caregivers}

The distribution of respondents by age, religion, education and marital status is represented in Table 1 above. The table shows that Christians were $359(94.5 \%)$ constituting the majority of respondents, followed by traditionalists $21(5.5 \%)$. About $108(28.4 \%)$ respondents reported to have attended primary school, $145(38.2 \%)$ secondary education, $69(18.1 \%)$ tertiary education while $58(15.3 \%)$ had no formal education. A larger proportion of the respondents $283(74.5 \%)$ were married while $82(21.6 \%)$ were single.

Table 2 shows the distribution of respondents by their occupation, level of income and number of children delivered. One hundred and fourteen $(30.0 \%)$ were business women or traders, $89(23.4 \%)$ farmers and $71(18.7 \%)$ civil servants. $170(44.7 \%)$ were low income earners per month ranging from (Nigerian currency; Naira - $\mathrm{N}$ ); N5,000- $N 18,000,79(20.8 \%)$ middle income earners ( $\mathrm{N} 18,000-50,000)$, while only $25(6.6 \%)$ were high income earners $(>\mathrm{A} 50,000)$. About $163(42.9 \%)$ reported to have had 1-3 times deliveries, $140(36.8 \%)$ 4-6 times deliveries and $77(20.3 \%)$ above 6 deliveries.

Table 2. Distribution of respondents by their occupation, level of income and number of children delivered $(\mathbf{N}=\mathbf{3 8 0})$

\begin{tabular}{|c|c|c|}
\hline Variables & $\begin{array}{l}\text { Number of } \\
\text { respondents }\end{array}$ & Percentages \\
\hline \multicolumn{3}{|l|}{ Occupation } \\
\hline Farmer & 89 & 23.4 \\
\hline Business/trader & 114 & 30.0 \\
\hline Unemployed & 61 & 16.1 \\
\hline Civil servant & 71 & 18.7 \\
\hline Full time housewife & 45 & 11.8 \\
\hline Total & 380 & 100 \\
\hline \multicolumn{3}{|l|}{$\begin{array}{l}\text { *Income level per } \\
\text { month }\end{array}$} \\
\hline Low & 170 & 44.7 \\
\hline Moderate & 79 & 20.8 \\
\hline High & 25 & 6.6 \\
\hline No response & 106 & 27.9 \\
\hline Total & 380 & 100 \\
\hline \multicolumn{3}{|c|}{ Number of children } \\
\hline $1-3$ & 163 & 42.9 \\
\hline $4-5$ & 140 & 36.8 \\
\hline$>6$ & 77 & 20.3 \\
\hline Total & 380 & 100 \\
\hline \multicolumn{3}{|c|}{$\begin{array}{c}{ }^{*} \text { Low income level = Less than } \mathrm{N} 20,000 ; \text { Moderate income } \\
\text { level = A 20,000 A 50,000; High income level = Above A } \\
50,000 .\end{array}$} \\
\hline $\begin{array}{r}\text { Exchange rate: } 1 \text { US Do } \\
(A) \text { a }\end{array}$ & $\begin{array}{l}\text { rs equivalent to } 1 \\
\text { at October } 2015 \\
\text { laracteristics of re }\end{array}$ & $\begin{array}{l}65 \text { Nigerian Naira } \\
\text { spondents }\end{array}$ \\
\hline
\end{tabular}

The socio-economic characteristics of respondents is represented in Table 3. In $335(88.1 \%)$ households, fathers were reported to be the heads of house while $45(11.9 \%)$ mothers were heads in other houses. Monogamous homes $316(83.2 \%)$ out-numbered polygamous homes 64(16.8\%). About 195(51.3\%) had household size between 1-3, 152(40.0\%) 4-6 and $33(8.7 \%) 7-10$. The family type predominant in the study area was nuclear family $275(72.4 \%)$ whereas about $105(27.6 \%)$ respondents resided with their extended families. Most respondents utilized pit latrine while $39(10.3 \%)$ used water system/closet. Their sources of drinking water were mainly from the streams $259(68.2 \%)$, tap/pipe borne $76(20.0 \%)$ and dug well $45(11.8 \%)$. More than half of the respondents $292(76.8 \%)$ reported substantial availability of food, whereas $88(23.2 \%)$ reported inadequate availability of food due to high cost of food stuff and lack of money $29(32.9 \%)$. 
Table 3. Socio-economic characteristics of respondents $(\mathrm{N}=\mathbf{3 8 0})$

\begin{tabular}{|c|c|c|}
\hline Variables & $\begin{array}{l}\text { Number of } \\
\text { respondents }\end{array}$ & Percentages \\
\hline \multicolumn{3}{|l|}{ Head of household } \\
\hline Father & 335 & 88.1 \\
\hline Mother & 45 & 11.9 \\
\hline Total & 380 & 100 \\
\hline \multicolumn{3}{|l|}{ Type of home } \\
\hline Monogamous home & 316 & 83.2 \\
\hline Polygamous home & 64 & 16.8 \\
\hline Total & 380 & 100 \\
\hline \multicolumn{3}{|l|}{ Household size } \\
\hline $1-3$ & 195 & 51.3 \\
\hline $4-6$ & 152 & 40.0 \\
\hline $7-10$ & 33 & 8.7 \\
\hline Total & 380 & 100 \\
\hline \multicolumn{3}{|l|}{ Type of family } \\
\hline Nuclear & 275 & 72.4 \\
\hline Extended & 105 & 27.6 \\
\hline Total & 380 & 100 \\
\hline \multicolumn{3}{|l|}{ Toilet facility } \\
\hline Pit latrine & 291 & 76.8 \\
\hline Water system/closet & 89 & 23.2 \\
\hline Total & 380 & 100 \\
\hline \multicolumn{3}{|l|}{ Sources of drinking } \\
\hline water & 259 & 68.2 \\
\hline Stream & 45 & 11.8 \\
\hline Dug well & 76 & 20.0 \\
\hline Tap/pipe borne & 380 & 100 \\
\hline \multicolumn{3}{|l|}{ Total } \\
\hline \multicolumn{3}{|l|}{ Food availability } \\
\hline Enough food available & 282 & 76.8 \\
\hline $\begin{array}{l}\text { Food available not } \\
\text { enough }\end{array}$ & 88 & 23.2 \\
\hline Total & 380 & 100 \\
\hline \multicolumn{3}{|l|}{$\begin{array}{l}\text { Reasons for food } \\
\text { inadequacy }\end{array}$} \\
\hline High cost of food stuffs & 51 & 58.0 \\
\hline $\begin{array}{l}\text { Lack of enough money } \\
\text { to buy more food stuffs }\end{array}$ & 29 & 32.9 \\
\hline Scarcity of food stuffs & 8 & 9.1 \\
\hline Total & 88 & 100 \\
\hline
\end{tabular}

\subsection{Nutritional Status of Under-five Children by Age and Gender}

The nutritional status of under-five children based on weight-for-age (underweight), heightfor-age (stunting) and weight-for-height (wasting) is represented in Tables 4,5 and 6 . Table 4 shows that a majority of children $272(71.6 \%)$ had normal Z-score for stunting, whereas 92(24.2\%) and $16(4.2 \%)$ were moderately and severely stunted respectively. Children aged $37-48$ months were more stunted than children of other age groups and the difference was not statistically significant $(p>0.05)$. The female children $202(53.2 \%)$ were more stunted than the male children $178(46.8 \%)$ with a statistically significant difference $(p<0.05)$.
With respect to weight-for-height (wasting) (Table $5)$, most under-five children $333(87.6 \%)$ had normal Z-scores while the remaining $45(11.5 \%)$ and $2(0.5 \%)$ were moderately and severely malnourished respectively. Children aged 25-36 months were more wasted than children of other age groups. Female children $27(7.2 \%)$ were more wasted than males 20(5.3\%). There was significant difference $(p<0.05)$ in the mean $Z$ score for both males and females.

Table 6 indicates that most (underweight) underfive children $273(71.8 \%)$ had normal Z-scores, while the remaining $91(23.9 \%)$ and $16(4.2 \%)$ were respectively moderately and severely malnourished. Children aged 37-48 months were more underweight than children of other age groups but this was not statistically significant difference. There was significant difference $(p<$ $0.05)$ between the Z-scores of the sexes.

The prevalence of stunting, wasting and underweight among the 380 under-five children is presented as $108(28.4 \%), 47(12.3 \%)$ and $107(28.1 \%)$ respectively (Fig. 1 ).

Table 4. Stunting (height-for-age) among under-five children by gender $(\mathbf{N}=\mathbf{3 8 0})$

\begin{tabular}{llll}
\hline & Male (\%) & Female (\%) & Total (\%) \\
\hline Normal & $132(34.7)$ & $140(36.8)$ & $272(71.6)$ \\
Moderate & $40(10.5)$ & $52(13.7)$ & $92(24.2)$ \\
Severe & $6(1.6)$ & $10(2.6)$ & $16(4.2)$ \\
Total & $178(46.8)$ & $202(53.2)$ & $380(100)$ \\
\hline
\end{tabular}

\subsection{Factors Affecting Malnutrition among Under-five Children}

These factors are presented in Table 7. The table shows that sex $(p<0.05)$ and age $(p<0.05)$ of child, poor mothers' knowledge of child nutrition $(p<0.05)$, large household size $(p<$ $0.05)$ and low income level $(p<0.05)$ were found to be statiscally significantly associated with malnutrition among under-five children. While, low maternal education ( $p>0.05$ ), women unemployment $(p>0.05)$ and poor child feeding pattern $(p>0.05)$ were not statistically significant associated with malnutrition.

Table 5. Wasting (weight-for-height) among under-five children by gender $(N=380)$

\begin{tabular}{llll}
\hline & Male (\%) & Female (\%) & Total (\%) \\
\hline Normal & $158(41.6)$ & $175(46.1)$ & $333(87.6)$ \\
Moderate & $18(4.7)$ & $27(7.1)$ & $45(11.8)$ \\
Severe & $2(0.5)$ & $0(0.0)$ & $2(0.5)$ \\
Total & $178(46.8)$ & $202(53.2)$ & $380(100)$ \\
\hline
\end{tabular}


Table 6. Underweight (weight-for-age) among under-five children by gender $(\mathrm{N}=380)$

\begin{tabular}{llll}
\hline & Male (\%) & Female (\%) & Total (\%) \\
\hline Normal & $132(34.7)$ & $141(37.1)$ & $273(71.8)$ \\
Moderate & $39(10.3)$ & $52(13.6)$ & $91(23.9)$ \\
Severe & $7(1.8)$ & $9(2.4)$ & $16(4.2)$ \\
Total & $178(46.8)$ & $202(53.2)$ & $380(100)$ \\
\hline
\end{tabular}

\section{DISCUSSION}

This study of the nutritional status of under-five children of Ekureku Community revealed that the prevalence of stunting, wasting and underweight in under-five children were $28.4 \%, 12.3 \%$ and $28.1 \%$ respectively; malnutrition was significantly higher among female children than males $(p=0.000)$. This finding is comparable with other studies carried out within and outside Nigeria
$[16,17,18]$. The prevalence of stunting in this study is lower than $48.7 \%$ in India [17], $30.7 \%$ in Ethiopia [18] and $46 \%$ in Oyo [16]. However, the prevalence was higher than $14.2 \%$ reported in Kaduna, Nigeria [19]. The differences might be attributed to the method of anthropometric assessment, study design used, number of study participants and study setting (urban or rural). However, our results show that undernutrition was a significant public health problem since all the prevalance for the three indices were above the cut-off values [1]. The older children were more at risk of being stunted than younger children, as children within the age group of 3748 months were more stunted than children of other age groups. This may be attributed to factors such as poor caring practices, chronic low dietary intake, exposure to infection such as diarrhoea and poor breastfeeding practices.

Table 7. Factors influencing nutritional status among under-five children $(\mathrm{N}=\mathbf{3 8 0})$

\begin{tabular}{|c|c|c|c|c|c|c|c|c|}
\hline \multirow[t]{2}{*}{ Variables } & \multicolumn{4}{|c|}{ Prevalence (\%) } & \multirow[t]{2}{*}{ Critical $x^{2}$} & \multirow[t]{2}{*}{$x^{2} 0.05$} & \multirow[t]{2}{*}{ df } & \multirow[t]{2}{*}{ P-value } \\
\hline & $\begin{array}{l}\text { Stunting } \\
(n=108)\end{array}$ & $\begin{array}{l}\text { Wasting } \\
(n=47)\end{array}$ & $\begin{array}{l}\text { Under } \\
\text { weight } \\
(n=107)\end{array}$ & $\begin{array}{l}\text { Total } \\
(n=262)\end{array}$ & & & & \\
\hline Age (in months) & & & & & 8.9910 & 15.51 & 8 & $0.000^{*}$ \\
\hline$\leq 24$ & $23(6.1)$ & $11(2.9)$ & $23(6.1)$ & $57(15.0)$ & & & & \\
\hline$\overline{2} 5-36$ & $26(6.8)$ & 14(3.7) & $24(6.3)$ & $64(16.8)$ & & & & \\
\hline $37-48$ & $32(8.4)$ & $12(3.2)$ & $31(8.2)$ & $75(19.7)$ & & & & \\
\hline $49-59$ & $27(7.1)$ & $10(2.6)$ & $29(7.6)$ & $66(17.4)$ & & & & \\
\hline Sex & & & & & 11.09 & 5.99 & 2 & $0.000^{*}$ \\
\hline Male & $46(12.1)$ & $20(5.3)$ & $46(12.1)$ & $112(29.5)$ & & & & \\
\hline Female & $62(16.3)$ & $27(7.1)$ & $61(16.1)$ & $150(39.5)$ & & & & \\
\hline Maternal education & & & & & 18.1172 & 12.59 & 6 & 0.433 \\
\hline No formal & $19(5.0)$ & $15(3.9)$ & $17(4.5)$ & $51(13.4)$ & & & & \\
\hline Primary & $40(10.5)$ & $12(3.2)$ & $41(10.8)$ & $93(24.5)$ & & & & \\
\hline Secondary & $39(10.3)$ & $12(3.2)$ & $38(10.0)$ & $89(23.4)$ & & & & \\
\hline Tertiary & $10(2.6)$ & $8(2.1)$ & $11(2.9)$ & $29(7.6)$ & & & & \\
\hline $\begin{array}{l}\text { Knowledge of child } \\
\text { Nutrition }\end{array}$ & & & & & 24.0122 & 5.99 & 2 & $0.002^{*}$ \\
\hline $\begin{array}{l}\text { Have knowledge } \\
\text { Do not have adequate }\end{array}$ & $52(13.7)$ & $19(5.0)$ & $49(12.9)$ & $120(31.6)$ & & & & \\
\hline knowledge & $56(14.7)$ & $28(7.4)$ & $58(15.3)$ & $142(37.4)$ & & & & \\
\hline Occupation & & & & & 11.14 & 5.99 & 2 & 0.368 \\
\hline Employed & $33(3.7)$ & $23(6.1)$ & $31(8.2)$ & $87(22.9)$ & & & & \\
\hline Unemployed & $75(19.7)$ & $24(6.3)$ & $76(20.0)$ & $175(46.1)$ & & & & \\
\hline Income level & & & & & 15.7200 & 9.49 & 4 & $0.004^{*}$ \\
\hline Low & $70(18.4)$ & $29(7.6)$ & $69(18.2)$ & $168(44.2)$ & & & & \\
\hline Moderate & $29(7.6)$ & 15(3.9) & $29(7.6)$ & $73(19.2)$ & & & & \\
\hline High & $9(2.4)$ & $3(0.79)$ & $9(2.4)$ & $21(5.5)$ & & & & \\
\hline Household size & & & & & 4.8462 & 9.49 & 4 & $0.000^{*}$ \\
\hline $1-3$ & $47(12.4)$ & $21(3.5)$ & $47(12.4)$ & $116(30.5)$ & & & & \\
\hline $4-6$ & $49(12.9)$ & $20(5.3)$ & $49(12.9)$ & $119(31.3)$ & & & & \\
\hline$>6$ & $12(3.2)$ & $6(1.6)$ & $11(2.9)$ & $27(7.1)$ & & & & \\
\hline Child feeding pattern & & & & & 9.8712 & 5.99 & 2 & 0.234 \\
\hline Correct feeding pattern & $53(13.9)$ & 12(3.2) & $50(13.2)$ & $115(30.3)$ & & & & \\
\hline Incorrect feeding pattern & $55(14.5)$ & $35(9.2)$ & $57(15.0)$ & $147(38.7)$ & & & & \\
\hline
\end{tabular}




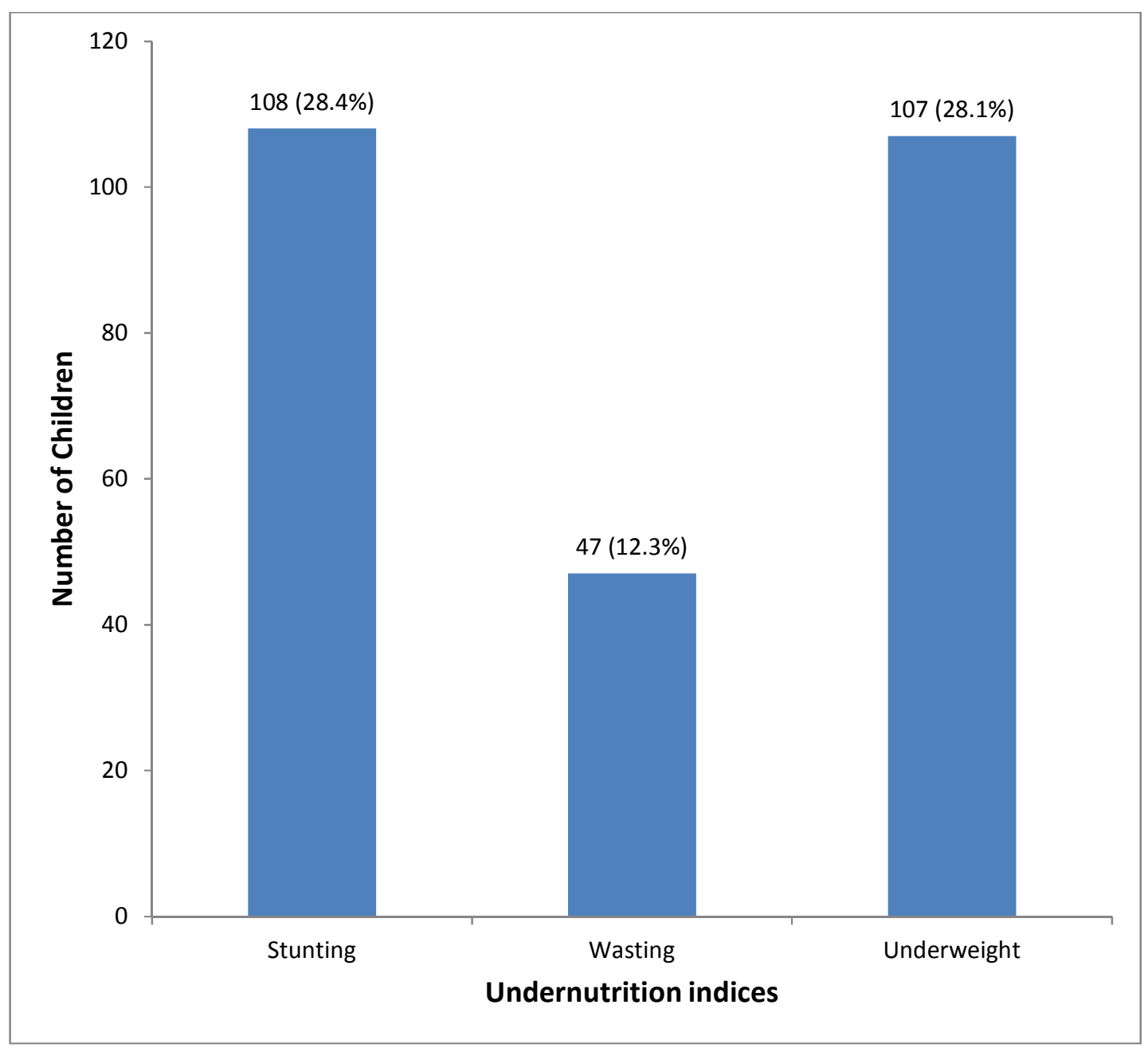

Fig. 1. Prevalence of malnutrition among children under-five years $(N=380)$

This study shows that females $(16.3 \%)$ were shorter than their male counterparts (12.1\%) and the difference was statistically significant $(p<0.05)$ (Table 7$)$. This report does not agree with an Indian study where girls were taller than boys [17]. The disparity could be attributed to gender bias, family set-up, diet pattern, parental preferences for male children $[20,21]$ and could be genetic [22].

The prevalence of wasting in this study (12.3\%) (Fig. 1) was higher than $3.7 \%$ reported in Northern Nigeria [23] and 5.5\% in Botswana [24], but lower than $21 \%$ in Oyo, Nigeria [16], $14.8 \%$ in Ondo, Nigeria [25] and 19\% in Sudan [26]. These differences could be associated with differences in extended periods of inadequate food intake, poor dietary quality, increased morbidity, household food insecurity, or a combination of these factors which were reported by [27]. In this study, children within 25-36 months were more likely to be thinner than children of other age groups, indicating that older children have a higher risk of wasting than their younger counterparts. Female children (7.1\%) appeared to be thinner than male children $(5.3 \%)$. The gender differences in wasting was statistically significant $(p<0.05)$. This finding is at variance with that of Fetuga et al. [19] where boys were found to be thinner than girls.

In this study, the prevalence of underweight is higher than the ones reported in other works $[24,2,23,25]$. The difference in the prevalence of reported underweight may be attributed to the sample size, method of nutritional assessment and study design, study setting (urban and rural), dietary pattern, increase in morbidity and large family size. Weight-for-age appeared to increase progressively with age of which children aged 37- 
48 months weighed more, and those within 0-12 months were heavier than other age groups. Male children (12.1\%) were less underweight than their female counterparts $(16.1 \%)$ and the difference was statistically significant $(p<0.05)$. This result contradicts the finding of Fetuga et al. [19]. The gender differences observed in underweight children could be attributed to state of health of children, exposure rate to infectious diseases, birth order, large family size, low food intake and lack of parental care.

Major factors affecting nutritional status were identified as sex of child, maternal education, knowledge of child nutrition, occupation, income level and child feeding practices. This study revealed that malnutrition was more prevalent among females than male children. Some other studies have proved otherwise [24,19]. In this study, however, the situation based on gender varies and may depend on child birth order, socio-economic status of parents, level of literacy and knowledge of good nutrition. In societies and cultures where male children are preferred to female children, nutrition plays a vital role in such gender disparity and consequently determines the growth of the child. Moreover, children from poorer homes tend to be susceptible to malnutrition than those from richer homes.

Maternal education also influences nutritional status among under-five children. It was observed in this study that children of mothers who had attained tertiary education were better nourished as compared to children whose mothers had low educational status (Table 7). This report was similar to that of Lawoyin et al. [27] where low parental education was associated with high risk of malnutrition. Most mothers with no formal education have been observed not to give colostrum and exclusive breasfeeding to their children [25], indicating that mothers with higher educational status tend to be more knowledgeable on the nutritional requirements of children at various stages of their growth.

Mothers' knowledge of child nutrition was identified as one of the factors determining malnutrition. This agrees with the studies of Nguyen and Nguyen [28] and Joshi et al. [29]. This indicates that effective dissemination of information on child nutrition will increase mothers' knowledge of the right kind of food to give their children at every stage of their growth and development.
Mothers' occupation was also identified as a risk factor associated with malnutrition in children. This agrees with other studies [28,29]. However, children whose mothers were gainfully employed were better nourished as well as fed than children whose mothers were unemployed, as observed in this study. Also, it was observed that children of high income earners appeared to be well-nourished than their counterparts (Table 7) as supported by $[29,25]$. Also identified as a determinant of nutritional status, was child feeding practice. Poor feeding practices increase children's susceptibility to malnutrition as reported by Ibrahim and Alshiek [26]. Mallik et al. [30] further report that children breastfed exclusively within their first six months of life tend to be better nourished than children who were not breastfed exclusively. Thus, children of mothers with lower socio-economic status have a higher risk of being malnourished than those whose mothers have higher socio-economic status. It is concluded that these factors, either synergistically or independently, can profoundly promote malnutrition in under-five children in Ekureku community.

\section{CONCLUSION}

Malnutrition is not a common factor in rural and some urban communities in developing countries where access to healthy and nutritious food is a problem. Coupled to this is the lack of adequate socioeconomic potentials that rural women have to cope with resulting in poor and undernourished homes and equally malnourished children under five years.

The world food programme addresses mostly war ravaged and famine struck areas of the world. There is a need however to extend the benefits of the programme to rural communities of developing economies to save starving children due to a general economic hardship afflicting mothers in these areas.

\section{CONSENT}

As per international standard or university standard, patient's written consent has been collected and preserved by the authors.

\section{ETHICAL APPROVAL}

As per international standard or university standard, written approval of Ethics committee has been collected and preserved by the authors. 


\section{COMPETING INTERESTS}

Authors have declared that no competing interests exist.

\section{REFERENCES}

1. WHO. Global nutrition policy review: What does it take to scale up nutrition actions? World Health Organization; Geneva; 2013a.

2. Babatunde RO, Olagunju FI, Fakayo SD, Sola-Ojo FE. Prevalence and determinants of malnutrition among under-five children of farming households in Kwara State, Nigeria. J Agric Sc. 2011;3(3):176-181.

3. UNICEF. The state of the world's children 2009, special edition: Celebrating 20 years of the convention on the rights of the child. New York, United Nations Children's Fund. 2009;92.

4. Black RE, Allen LH, Butta ZA, Caulfield LE, de Onis M, Ezzati M, Mathers C, Rivera J. Maternal and child undernutrition: Global and regional exposures and health consequences. Lancet. 2008;371(9608): 243-260.

5. WHO. Updates of the management of severe acute malnutrition in infants and children. Geneva; 2013b.

6. Goel MK, Mishra R, Gaul DR, Das A. Nutrition surveillance in 1-6 years old children in urban slums of a city in Northern India. Int J Epidemiol. 2007;5: 111-119.

7. UNICEF. The state of the world's children 2007, Women and children, New York; 2007.

8. National Population Commission and ICF International. Nigeria Demographic and Health Survey (NDHS). National Population Commission and ICF International; 2014. ID: FR293

9. Action Against Hunger. Maximizing the nutritional impact of food security and livelihood interventions: A manual for field workers.

Available:www.actionagainsthunger.org/.../ 2011/.../maximising-nutritional-impact

10. Yunusa I, Gumel AH, Adegbusi KAS. School feeding program in Nigeria: A vehicle for nourishment of pupils. The African symposium. An Outline Journal of the African Educational Research Network. 2012;12(2).
Available:http:/www.ncsu.edu/aern/TAS12. 2/TAS12.2 yunusa.pdf

11. Alom J, Qudelus MA, Islam MA. Nutritional status of under-five children in Bangladesh: A multilevel analysis. J Biosocial Sc. 2012;44(5):525-535.

12. Ejemot-Nwadiaro RI, Ehiri JE, Arikpo D, Meremikwu MM, Critchley M. Handwashing promotion for preventing diarrhea. Cochrane Database of Systematic Review. John Wiley and Sons Ltd., Oxford; 2015.

13. Hemel C, Enne J, Omer K, Ayara N, Yarima Y, Cockroft A, Anderson N. Childhood malnutrition is associated with maternal care during pregnancy and childbirth: A cross-sectional study in Bauchi and Cross River State, Nigeria. J Pub Health Res. 2015;4(1):139-148.

14. Mashal T, Takano T, Nakamura K, Kizuki M, Harmat S, Waranbe $M$, Seinok L. Factors associated with the health and nutritional status of children under 5 years of age in family behaviour related to women and past experience of war-related hardships. BMC Pub Health. 2008;8(301): 1471-2458.

15. Odunayo SI, Oyewole AO. Risk factors of malnutrition among rural Nigerian children. Asian Pacific J Clin Nutr. 2006;15(4):491495.

16. Awoyemi TT, Odozi JC, Oguniyi AA. Environmental and socio-economic correlates of child malnutrition in Iseyin Area of Oyo State, Nigeria. Food and Pub Health. 2012;2(4):92-98.

17. Maken T, Varte LR. Nutritional status of children as indicated by Z-scores of the Hmars: A tribe of N. E. India. Antrocom Online J Anthropol. 2012;8(1):213-227.

18. Mekonnen $\mathrm{H}$, Tadesse $\mathrm{T}$, Kisi $\mathrm{T}$. Malnutrition and its correlates among rural primary school children of Fogera District, Northwest Ethiopia. Nut Disorder Therapy. 2013;4(1):1-7.

19. Fetuga MB, Ogunlesi TA, Adekanmbi AF, Alabi AD. Nutritional status of semi-urban Nigerian school children using the 2007 WHO Reference population. West Afr J Med. 2011;30(5):331-336.

20. Nyaruhucha CM, Msuya JM, Mamiro PS, Kerengi AJ. Nutritional status and feeding practices of under-five children in Samanjiro District, Tanzania. Tanzanian Health Res Bull. 2000;8(3):162-167. 
21. Chaudhury RH. Effects of mothers' work on childcare, dietary intake and dietary inadequacy of pre-school children. International Food and Nutrition Program, Massachusetts Institute of Technology, Massachusetts; 1983.

22. Estourgie-van Burk $G$, Bartels $M$, Van Beysteveldt T, Delemarre-van de Waal HA, Boomsnia DI. Body size in five-year old twins: Heritability and comparison to singleton standards. Twin Res Human Gen. 2006;9(5):646-655.

23. Aliyu AA, Oguntunde OO, Dahiru T, Raji T. Prevalence and determinants of malnutrition among pre-school children in Northern Nigeria. Pakistern $J$ Nut. 2012;11(1):1092-1095.

24. Mahgoub SEO, Nnyepi M, Bandeke T. Factors affecting prevalence of malnutrition among children under three years of age in Botswana. Afr J Food Agric Nutrition Dev. 2006;6(1):1684-5374.

25. Akorede QJ, Abiola OM. Assessment of nutritional status of under-five children in Akure South Local Government Area, Ondo State, Nigeria. Int J Res Rev Appl Sc. $2013 ; 14(3): 671-681$.
26. Ibrahim MM, Alshiek $\mathrm{MH}$. The impact of feeding practices on prevalence of undernutrition among 6-59 months aged children in Khartoum. Sudanese J Pub Health. 2010;5(3):151-157.

27. Olack B, Burke H, Cosmas L, Bamrah S, Dooling K, Feikin DR, Talley LE, Breiman RF. Nutritional status of under-five children living in an informal urban settlement in Nairobi, Kenya. J Health Pop Nut. $2011 ; 29(4): 357-363$.

28. Nguyen $\mathrm{NH}$, Nguyen $\mathrm{NH}$. Nutritional status and determinants of malnutrition in children under three years of age in Nghean, Vietnam. Pakistan J Nut. 2009;8:958964.

29. Joshi HS, Gupta R, Joshi ML, Mahajan V. Determinants of nutritional status of school children. Nat J Integrated Res Med. 2011;2(1):10-15.

30. Mallik S, Dasgupta U, Naskar S, Sengupta D, Choudhury K, Bhattacharya SK. Knowledge of breastfeeding and timely initiation of it among post-natal mothers: An experience from a baby friendly teaching hospital of metropolitan city. J Dental Med Sc. 2013;4(1):25-30.

(c) 2017 Donatus et al.; This is an Open Access article distributed under the terms of the Creative Commons Attribution License (http://creativecommons.org/licenses/by/4.0), which permits unrestricted use, distribution, and reproduction in any medium, provided the original work is properly cited.

Peer-review history:

The peer review history for this paper can be accessed here: http://sciencedomain.org/review-history/19133 